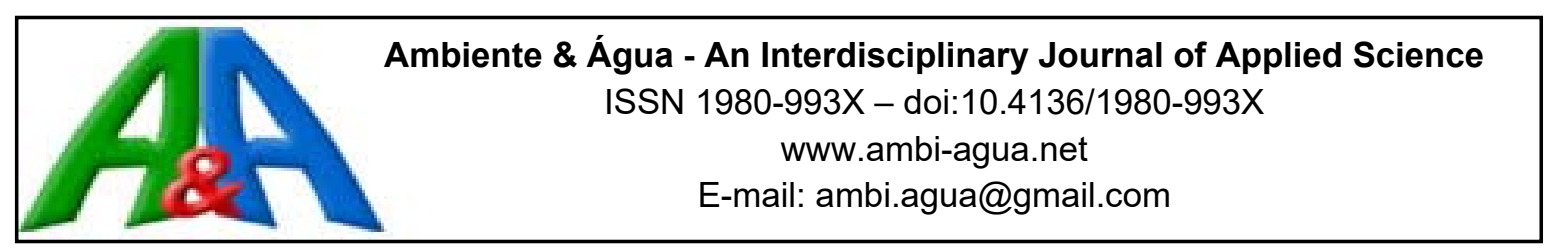

\title{
Análise bacteriológica da água de consumo comercializada por caminhões-pipa
}

\author{
doi:10.4136/ambi-agua.1934
}

Received: 08 May. 2016; Accepted: 18 Feb. 2017

\author{
Maria Helena Martins Mendonça ${ }^{1}$; Sthefany Angely Moraes Roseno'; \\ Thayany Ruanny Leite Cachoeira ${ }^{1}$; Ákylla Fernanda Souza Silva ${ }^{1}$; \\ Paula Regina Luna de Araújo Jácome ${ }^{2}$; Agenor Tavares Jácome Júnior ${ }^{1 *}$

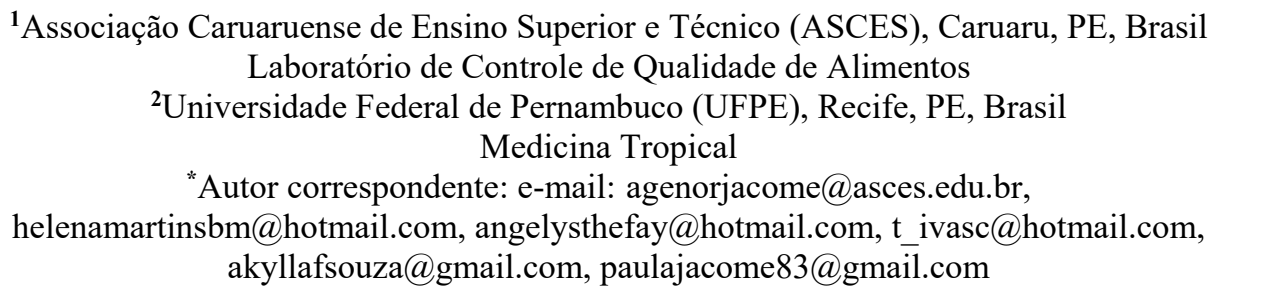

\section{RESUMO}

A garantia do fornecimento de uma água de qualidade destinada ao consumo humano é uma questão relevante para a saúde pública, sobretudo quando a água ofertada é dependente de meios alternativos, como os chamados caminhões-pipa. Entretanto, a grande preocupação quanto a esse tipo de transporte de água está relacionada aos diversos riscos de contaminações que podem ocorrer. Assim, o presente estudo teve como objetivo avaliar a qualidade bacteriológica da água para consumo direto (ingestão) comercializada por caminhões-pipa, destinada ao abastecimento da cidade de Caruaru-PE. Foram analisadas 10 amostras, obtidas de cinco caminhões-pipa, por meio da Técnica dos Tubos Múltiplos, para a identificação de Pseudomonas aeruginosa e do grupo coliforme e, da técnica pour plate, para a contagem de bactérias heterotróficas. Os resultados revelaram a presença dos grupos bacterianos testados na maioria das amostras analisadas. Foi verificado que o tempo era um fator que contribuia para o aumento do índice de contaminação. Conclui-se que esse tipo de comércio acaba fornecendo uma água que não atende aos requisitos de potabilidade e com um alto risco de contaminação, sendo imprópria para o consumo humano.

Palavras-chave: água potável, coliforme, Pseudomonas aeruginosa.

\section{Bacteriological analysis of drinking water sold by water tank trucks}

\begin{abstract}
Assuring the quality of the supply of water for human consumption is important for public health, especially when delivery of the water is dependent on alternative means, such as tanker trucks. The major concern about this kind of water transport is the risk of contamination. This study therefore evaluated the bacteriological quality of water sold by water trucks that supply the city of Caruaru-PE, Brazil. Ten samples from five trucks were analyzed using the technique of multiple tubes for the identification of Pseudomonas aeruginosa and coliform, and the pour plate technique for counting heterotrophic bacteria was also used. The results revealed the
\end{abstract}


presence of bacteria groups in most analyzed samples. Delivery time was a factor that increases the rate of contamination. It can be concluded that this type of delivery provides water that does not meet potability requirements and has a high risk of contamination, resulting in water that is unfit for human consumption.

Keywords: coliforms, potable water, Pseudomonas aeruginosa.

\section{INTRODUÇÃO}

A água é considerada um recurso natural insubstituível, tendo fundamental importância para a manutenção da vida. O controle da qualidade da água é uma necessidade universal, que exige atenção por parte das autoridades sanitárias e dos consumidores em geral, sobretudo no que se refere à água destinada ao consumo humano, visto que ela pode se tornar um veículo capaz de transmitir uma série de agentes patogênicos e substâncias nocivas influenciando diretamente no bem-estar e na saúde da população (Araújo et al., 2011; Wang et al., 2014).

Caruaru é um município localizado na região do agreste pernambucano, a 130 quilômetros da capital, Recife. Sua população estimada pelo Instituto Brasileiro de Geografia e Estatística no ano de 2015, foi de 347.088 habitantes, com área territorial de $920,611 \mathrm{~km}^{2}$ (IBGE, 2015). É prática comum no município a comercialização de água, dita "potável e mineral", em caminhões transportando até seis containers (cujas especificações são para transporte de peixe vivo) com capacidade para $1.000 \mathrm{~L}$ de água. Essa água é obtida diretamente de fontes naturais, sendo coletadas de aquíferos subterrâneos da região. A água captada passa por uma etapa de cloração e em seguida é livremente vendida em garrafões com capacidade para $20 \mathrm{~L}$, sendo a água envasada apenas no momento da sua comercialização.

Os caminhões que fazem o transporte da água para o consumo ou outras finalidades de uso doméstico (caminhões-pipa) devem garantir que a água distribuída seja potável e seguir todos os procedimentos citados na Portaria 2914/11 (MS) estabelecido no Artigo 15. Essa mesma portaria estabelece os padrões de potabilidade para essas águas, de modo que o seu consumo não ofereça riscos à saúde. Entretanto, a grande preocupação quanto ao comércio da água para o consumo em caminhões-pipa é referente aos diversos riscos de contaminações que ela está exposta, podendo ser comercializada fora dos padrões de qualidade e ainda servir como propagadora de diversas doenças (Carvalho, 2015).

Nesse sentido, o monitoramento da qualidade bacteriológica da água para consumo deve ser realizado a fim de se avaliar se ela se encontra dentro dos padrões de potabilidade humana, que requer uma água limpa e livre de patógenos ou qualquer outro tipo de contaminação que cause danos à saúde (Müller e Parussolo, 2014). Para que essa qualidade seja estabelecida, são utilizados como parâmetro, micro-organismos indicadores de contaminação fecal, como o grupo Coliforme, tendo como principal representante a Escherichia coli, que avalia suas condições higiênicas evidenciando uma possível contaminação fecal recente (Coelho et al., 2010; Cavalcante, 2014; Silva et al., 2016).

Além do grupo coliforme, a pesquisa da bactéria Pseudomonas aeruginosa, em ambientes aquáticos, tem-se mostrado de grande importância, sobretudo em águas destinadas ao consumo humano, como as águas minerais (Almeida et al., 2009; Pedrosa et al., 2014). Trata-se de um bacilo gram-negativo, sendo classificado como um dos micro-organismos mais versáteis e oportunistas. Sua presença está relacionada às diversas causas de infecções devido à colonização de dispositivos médicos e a consequente formação de biofilme, ocasionando em importantes complicações clínicas e elevados custos associados ao manejo dos pacientes (Quatrin et al., 2015).

Levando em consideração que o consumo de uma água fora dos padrões estabelecidos pela legislação pode ocasionar diversos riscos à saúde da população, o presente trabalho teve como 
objetivo avaliar a qualidade bacteriológica das águas para consumo direto (ingestão) comercializadas em "Caminhões-pipa" do município de Caruaru-PE. A determinação da qualidade bacteriológica das águas será realizada pesquisando-se a presença de indicadores de contaminação fecal (grupo coliforme), de contaminação por material orgânico (a espécie Pseudomonas aeruginosa) e pela contagem de bactérias heterotróficas nas amostras de água coletadas.

\section{MATERIAL E MÉTODOS}

\subsection{Tipologia do estudo, coleta e amostragem}

O presente estudo possuiu um desenho experimental laboratorial. $\mathrm{O}$ universo da pesquisa foi composto por amostras de água para consumo direto (ingestão) comercializadas em "caminhões-pipa" na cidade de Caruaru-PE. As coletas foram realizadas no mês de dezembro de 2015 a fevereiro de 2016, sendo coletadas 10 amostras de água obtidas de 5 caminhões-pipa em diferentes pontos da Cidade de Caruaru-PE. As amostras foram coletadas em dois horários distintos, sendo das $09: 00 \mathrm{~h}$ às $11: 00 \mathrm{~h}$ para a primeira coleta, e das 14:00h às 16:00h para a segunda coleta.

Os critérios de elegibilidade para os caminhões-pipa eram, principalmente, o seu destino de abastecimento por todo o município, sobretudo nos bairros mais populosos; ser um caminhão de médio porte, com capacidade para até seis containers retangulares, que utilizassem para transportar água tanques para transporte de peixe vivo, com capacidade de $1.000 \mathrm{~L}$ em material de polietileno (PE); e que a água neles comercializada fosse advinda das fontes subterrâneas localizadas na reserva do Muricí, situada na zona rural do município de Caruaru-PE.

As amostras foram coletadas em botijões de 20L, previamente higienizados através de assepsia com álcool $70 \%$ e, logo em seguida, as amostras de cada caminhão-pipa eram distribuídas em sacos estéreis com capacidade para $140 \mathrm{~mL}$. Por fim, as amostras eram transportadas sobre refrigeração até o Laboratório de Análise de Água e Bromatologia localizado do Centro Universitário Tabosa de Almeida - ASCES/UNITA, em Caruaru-PE, para a realização das análises bacteriológicas.

\subsection{Análise microbiológica}

As pesquisas de $P$. aeruginosa e do grupo coliforme foram realizadas através da Técnica dos Tubos Múltiplos, método preconizado pelo Standard Methods for the Examination of Water and Wasterwater (APHA et al., 2012). As condições de cultivo para a pesquisa de $P$. aeruginosa foi utilizando o Caldo Asparagina em 3 séries de 5 tubos, com incubação de $35^{\circ} \mathrm{C} / 48 \mathrm{~h}$ para a fase presuntiva, e o Caldo Acetamida para a fase confirmatória na mesma temperatura e tempo de incubação. Para a pesquisa de coliformes foram utilizados os meios Caldo Lactosado (ensaio presuntivo) e Caldo Lactosado Verde Brilhante Bile (ensaio confirmatório) incubados à $35^{\circ} \mathrm{C} / 48 \mathrm{~h}$. A contagem de bactérias heterotróficas foi feita de acordo com a técnica de Pour Plate (APHA et al., 2012).

\subsection{Processamento de dados}

As análises dos dados foram conduzidas utilizando o software excel (v. 14.07) no qual foi aplicada uma análise descritiva para obtenção do percentual de positividade das amostras para $P$. aeruginosa, coliformes totais e termotolerantes, e a média e desvio padrão das contagens de bactérias heterotróficas dadas por unidades formadoras de colônias para cada mililitro de água (UFC mL $\mathrm{mL}^{-1}$ ). 


\section{RESULTADOS E DISCUSSÃO}

Os resultados aqui observados demonstraram que a grande maioria (90\%) das amostras de água comercializadas em caminhões-pipa analisadas nessa pesquisa apresentaram contagens de coliformes totais (CT), coliformes termotolerantes (CTo), Pseudomonas aeroginosa e bactérias heterotróficas em desacordo com padrões de potabilidade estabelecidos pela legislação vigente (Tabela 1). Apenas na amostra E, coletada no turno da manhã (E m), foi observada a ausência dos grupos bacterianos analisados, no entanto, a contagem de bactérias heterotróficas ainda

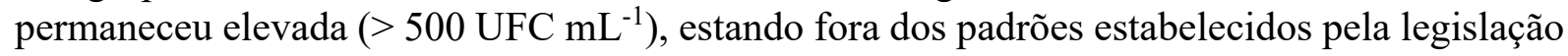
(Tabela 1).

Na Tabela 1 estão distribuídos os resultados relativos às determinações dos NMP (Número Mais Provável) de coliformes totais, termotolerantes e Pseudomonas aeroginosa por $100 \mathrm{ml}$ de água e Bactérias heterotróficas por UFC $\mathrm{mL}^{-1}$.

Tabela 1. Resultado da análise do Número Mais Provável (NMP) de coliformes totais, termotolerantes e Pseudomonas aeruginosa, e contagem de bactérias heterotróficas (UFC $\mathrm{ml}^{-1} \times 10^{3}$ ) em amostras de água para consumo humano comercializada por caminhões-pipa.

\begin{tabular}{|c|c|c|c|c|}
\hline Amostras & $\begin{array}{l}\text { Coliformes } \\
\text { Totais* }\end{array}$ & $\begin{array}{c}\text { Coliformes } \\
\text { Termotolerantes* }\end{array}$ & $\begin{array}{l}\text { Pseudomons } \\
\text { aeroginosa* }\end{array}$ & $\begin{array}{c}\text { Bactérias } \\
\text { Heterotróficas* }\end{array}$ \\
\hline $\mathrm{A}(\dot{\mathrm{m}})$ & $17 \mathrm{NMP} / 100 \mathrm{ml}$ & $9 \mathrm{NMP} / 100 \mathrm{ml}$ & $33 \mathrm{NMP} / 100 \mathrm{ml}$ & $4434 \pm 1168 \mathrm{UFC} \mathrm{ml}^{-1}$ \\
\hline $\mathrm{A}(\mathrm{T})$ & $>1600 \mathrm{NMP} 100 \mathrm{ml}$ & $90 \mathrm{NMP} / 100 \mathrm{ml}$ & $17 \mathrm{NMP} / 100 \mathrm{ml}$ & $4484 \pm 722 \mathrm{UFC} \mathrm{ml}^{-1}$ \\
\hline $\mathrm{B}(\dot{\mathrm{m}})$ & $11 \mathrm{NMP} / 100 \mathrm{ml}$ & $11 \mathrm{NMP} / 100 \mathrm{ml}$ & $11 \mathrm{NMP} / 100 \mathrm{ml}$ & $2817 \pm 471 \mathrm{UFC} \mathrm{m}^{-1}$ \\
\hline $\mathrm{B}(\mathrm{T})$ & $280 \mathrm{NMP} / 100 \mathrm{ml}$ & $17 \mathrm{NMP} / 100 \mathrm{ml}$ & $90 \mathrm{NMP} / 100 \mathrm{ml}$ & $3000 \pm 200 \mathrm{UFC} \mathrm{ml}^{-1}$ \\
\hline $\mathrm{C}(\dot{\mathrm{m}})$ & $4 \mathrm{NMP} / 100 \mathrm{ml}$ & $2 \mathrm{NMP} / 100 \mathrm{ml}$ & $11 \mathrm{NMP} / 100 \mathrm{ml}$ & $3097 \pm 453 \mathrm{UFC} \mathrm{ml}^{-1}$ \\
\hline $\mathrm{C}(\mathrm{T})$ & $9 \mathrm{NMP} / 100 \mathrm{ml}$ & $9 \mathrm{NMP} / 100 \mathrm{ml}$ & $21 \mathrm{NMP} / 100 \mathrm{ml}$ & $3600 \pm 530 \mathrm{UFC} \mathrm{ml}^{-1}$ \\
\hline $\mathrm{D}(\dot{\mathrm{m}})$ & $14 \mathrm{NMP} / 100 \mathrm{ml}$ & $12 \mathrm{NMP} / 100 \mathrm{ml}$ & $11 \mathrm{NMP} / 100 \mathrm{ml}$ & $2934 \pm 405 \mathrm{UFC} \mathrm{ml}^{-1}$ \\
\hline $\mathrm{D}(\mathrm{T})$ & $26 \mathrm{NMP} / 100 \mathrm{ml}$ & $7 \mathrm{NMP} / 100 \mathrm{ml}$ & $14 \mathrm{NMP} / 100 \mathrm{ml}$ & $3333 \pm 514 \mathrm{UFC} \mathrm{ml}^{-1}$ \\
\hline $\mathrm{E}(\dot{\mathrm{m}})$ & $<2 \mathrm{NMP} / 100 \mathrm{ml}$ & $<2 \mathrm{NMP} / 100 \mathrm{ml}$ & $<2 \mathrm{NMP} / 100 \mathrm{ml}$ & $3700 \pm 361 \mathrm{UFC} \mathrm{ml}^{-1}$ \\
\hline $\mathrm{E}(\mathrm{T})$ & 27 NMP/100ml & $90 \mathrm{NMP} / 100 \mathrm{ml}$ & $22 \mathrm{NMP} / 100 \mathrm{ml}$ & $4734 \pm 1070 \mathrm{UFC} \mathrm{ml}^{-1}$ \\
\hline
\end{tabular}

Nota: *A Portaria 2914/11MS estabelece como limites aceitáveis para coliformes totais e termotolerantes $<2 \mathrm{NMP} / 100 \mathrm{~mL}$, e para bactérias heterotróficas abaixo de $500 \mathrm{UFC} / \mathrm{mL}$. A Pseudomonas aeruginosa não é prevista por essa portaria, mesmo sendo considerada um indicador de contaminação por material orgânico. NMP - Número Mais Provável; (m) - manhã; (T) - tarde; UFC - Unidade Formadoras de Colônias.

De acordo com a Tabela 1, é possível observar que há aumento significativo na contagem microbiana das amostras coletadas na parte da tarde frente ao grupo coliforme e à espécie Pseudomonas aeruginosa, quando comparadas as análises bacteriológicas das amostras de água coletadas pela manhã (Tabela 2). Isso pode ser explicado pela influência de alguns fatores, tais como: a temperatura da água no interior do container de armazenamento, a idade da água, o material que compõem os containers dos caminhões-pipa e a reutilização dos mesmos sem uma prévia higienização. Os efeitos combinados destes fatores influenciam na abundância relativa 
de vários micro-organismos na água e, especificamente, sobre o número de bactérias totais e de patógenos oportunistas (Wang et al., 2014).

A reutilização dos containers na comercialização da água sem que seja submetido à etapas de desinfecções pode apresentar riscos do ponto de vista microbiológico, tornando-se uma possível fonte de contaminação (Carvalho, 2015). Esse fato está relacionado principalmente à ineficiência das etapas de limpeza dos containers, uma vez que o biofilme formado em seu interior não é facilmente removível (Farache Filho e Dias, 2008). Além disso, na embalagem da água mineral, rachaduras presentes na face interna podem ser locais adequados para o desenvolvimento de biofilmes e, consequentemente, a contaminação da água. Essa aderência pode explicar a longa sobrevivência deste micro-organismo, podendo sobreviver em águas envasadas por vários anos (Iwersen et al., 2009).

Tabela 2. Variação percentual (\%) dos parâmetros bacteriológicos, entre os períodos da manhã e da tarde, das amostras de água para consumo humano comercializadas por caminhões-pipa.

\begin{tabular}{ccccc}
\hline Amostras & $\begin{array}{c}\text { Coliformes } \\
\text { Totais }\end{array}$ & $\begin{array}{c}\text { Coliformes } \\
\text { Termotolerantes }\end{array}$ & $\begin{array}{c}\text { Pseudomonas } \\
\text { aeroginosa }\end{array}$ & $\begin{array}{c}\text { Bactérias } \\
\text { Heterotróficas }\end{array}$ \\
\hline A & 9312 & 900 & -48 & 4 \\
B & 2445 & 55 & 718 & 2 \\
C & 125 & 350 & 91 & -7 \\
D & 86 & -42 & 27 & 7 \\
E & 2600 & 8900 & 2100 & 32 \\
\hline
\end{tabular}

Um segundo fator que pode influenciar diretamente tanto no crescimento de micro-organismos, como no aumento da formação de biofilmes, é a temperatura, que quando elevada pode evaporar o cloro presente na água. Nesse estudo, foi observada que na parte da tarde as temperaturas encontravam-se naturalmente mais elevadas $\left(30 \pm 1^{\circ} \mathrm{C}\right)$ quando comparadas às temperaturas das amostras da mesma água coletada pela manhã $\left(20 \pm 1^{\circ} \mathrm{C}\right)$. Esses resultados foram semelhantes ao estudo realizado por Torvinen, et al. (2007) que observaram elevadas contagens microbianas com o aumento da temperatura nos sistemas de distribuição de água potável.

Outro fator a ser observado é a idade da água, ou seja, o tempo que água fica armazenada no interior dos containers dos caminhões durante a comercialização. Em um estudo realizado por Wang et al. (2014) foram observadas mudanças significativas na contagem microbiana relacionada à idade da água, o que pode ser explicado pelo efeito direto das mudanças nas condições físico-química da água durante o tempo em que fica armazenada no interior de containers de PVC. Com isso, dentre outras espécies, os autores observaram um aumento do número de Pseudomonas aeruginosa na água.

Além da temperatura e idade da água, o material do qual é composto os containers, o polietileno (PE), favorece o crescimento de micro-organismos na água, propiciando a adesão bacteriana às suas superfícies, sendo este, um dos passos iniciais para formação de biofilme. Isso agrava a contaminação da água, reduzindo a sua qualidade e aumentando a taxa de corrosão dos containers com consequente redução da segurança microbiológica através da sobrevivência de agentes patogênicos. Dentre os materiais utilizados o SS 316 e o policloreto de polivinila (PVC) foram termodinamicamente favoráveis para 6 tipos bacterianos, SS 304 para 18 tipos, e Copper, Polipropileno (PP) e Polietileno (PE) para 25 tipos de bactérias. A adesão é dependente 
da afinidade entre as propriedades físico-químicas da superfície bacteriana e dos materiais (Simões et al., 2007; Torvinen et al., 2007).

Com relação à contagem de bactérias heterotróficas, estas apresentaram um crescimento relativamente parecido nos dois horários de coleta (Tabela 2). No entanto, em ambas as coletas (manhã e tarde), essas contagens excederam o limite de 500 UFC mL-1, podendo ser consideradas impróprias para o consumo de acordo com os padrões de potabilidade estabelecidos pela portaria vigente (2914 MS/2011, Brasil, 2011), onde recomenda-se que a contagem de bactérias heterotróficas não ultrapasse o limite de $500 \mathrm{UFC} / \mathrm{mL}$.

\section{CONCLUSÃO}

A forma de comércio das águas destinadas ao consumo humano por caminhão-pipa no município de Caruaru-PE foi considerada imprópria para este fim, tendo em vista que a análise bacteriológica das mesmas apresentou baixo índice de potabilidade e um alto risco de contaminação por patógenos, fato este evidenciado pela presença dos coliformes fecais, Pseudomonas aeroginosa e pela elevada contagem de bactérias heterotróficas.

Desse modo, faz-se necessária uma fiscalização mais efetiva por parte dos órgãos responsáveis para o melhoramento dos recursos hídricos. É sugerido que seja realizado um monitoramento nos pontos de captação dos distribuidores e principalmente nos tanques que transportam a água comercializada, a fim de que haja a implantação de sistemas de controle como as Boas Práticas de Fabricação (BPF's) e as Análises de Perigos e Pontos Críticos de Controle (APPCC), garantindo que as propriedades naturais da água mineral sejam mantidas. Além disso, é fundamental a conscientização dos consumidores quanto ao seu direito em adquirir um produto de boa qualidade.

\section{AGRADECIMENTOS}

Agradecemos ao Laboratório Luiz Alberto Florêncio pelo apoio e incentivo.

\section{REFERÊNCIAS}

ALMEIDA, V. F. S.; OLIVEIRA, S. R.; JÁCOME, P. R. L. A.; JÁCOME-JÚNIOR, A. T. Avaliação de indicadores higiênico-sanitários e das características físico-químicas em águas utilizadas em escolas públicas de nível fundamental. Revista do Instituto Adolfo Lutz, v. 68, n. 3, p. 334-40, 2009.

AMERICAN PUBLIC HEALTH ASSOCIATION - APHA; AMERICAN WATER WORKS ASSOCIATON - AWWA; WATER ENVIRONMENT ASSOCIATION - WEF. Standard methods for the examination of water $\&$ wastewater. 22st edition. Washington, 2012. $1360 \mathrm{p}$.

ARAÚJO, G. F. R; TONANI, K. A. A.; RAGAZZI, M. F.; JULIÃO, F. C.; SAMPAIO, C. F.; CARDOSO, O. O. et al. Qualidade físico-química e microbiológica da água para o consumo humano e a relação com a saúde: estudo em uma comunidade rural no estado de São Paulo. O Mundo da Saúde, v. 35, n. 1, p. 98-104, 2011.

BRASIL. Ministério da Saúde. Portaria n 2914 de 12 de dezembro de 2011. Dispõe sobre os procedimentos de controle e de vigilância da qualidade da água para consumo humano e seu padrão de potabilidade. Diário Oficial [da] União, Poder Executivo, Brasília, DF, 12 mar. 2011. 
CARVALHO, A. M. Qualidade da água distribuída pelos caminhões-pipa para consumo humano. In: EXPOSIÇÃO DE EXPERIÊNCIAS MUNICIPAIS EM SANEAMENTO, 9., de 24 a 29 de maio de 2015, Poços de Caldas. Anais... Poços de Caldas: [s.n.], 2015.

CAVALCANTE, R. B. L. Ocorrência de Escherichia coli em fontes de água e pontos de consumo em uma comunidade rural. Revista Ambiente \& Agua, v. 9, n. 3, 2014. http://dx.doi.org/10.4136/ambi-agua.1301

COELHO, M. I. S.; MENDES, E. S.; CRUZ, M. C. S.; BEZERRA, S. S.; PINHEIRO, R. P. Avaliação da qualidade microbiológica de águas minerais consumidas na região metropolitana de Recife, Estado de Pernambuco. Acta Scientiarum. Health Sciences, v. 32, n. 1, p. 1-8, 2010. http://dx.doi.org/10.4025/actascihealthsci. v32i1. 3837

FARACHE FILHO, A.; DIAS, M. F. F. Qualidade microbiológica de águas minerais em galões de 20 litros. Alimentos e Nutrição Araraquara, v. 19, n. 3, p. 243-248, 2009.

INSTITUTO BRASILEIRO DE GEOGRAFIA E ESTATÍSTICA - IBGE. Estimativa da População de Caruaru no ano de 2015. Disponível em: https://goo.gl/NK9nCL https://goo.g1/NK9nCL. Acesso: 23 abril 2016

IWERSEN, A. T.; YAMANAKA, E. H. U.; LUZ JÚNIOR, L. F. D. L.; MOSNTEIRO, C. L. B.; COGO, L. L.; BEUX, M. R. Avaliação da qualidade microbiológica de águas minerais envasadas-dinâmica populacional de Pseudomonas aeruginosa. Boletim do Centro de Pesquisa de Processamento de Alimentos, v. 27, n. 2, 2009. http://dx.doi.org/10.5380/cep.v27i2.22030

MÜLLER, L. R.; PARUSSOLO, L. Qualidade microbiológica da água utilizada para consumo em escolas municipais de Mamborê, Paraná. SaBios-Revista de Saúde e Biologia, v. 9, n. 1, p. 95-99, 2014.

PEDROSA, A. P.; BRANDAO, M. L. L.; MEDEIROS, V. M.; ROSAS, C. O.; BRICIO, S. M. L; ALMEIDA, A. E. C. C; Pesquisa de fatores de virulência em Pseudomonas aeruginosa isoladas de águas minerais naturais. Revista Ambiente \& Água, v. 9, n. 2, p. 313-324, 2014. http://dx.doi.org/10.4136/ambi-agua.1359

QUATRIN, P. M.; COMIM, V. M.; LOPES, L. Q. S.; GÜNDEL, A.; ALMEIDA VAUCHER, R.; SANTOS, R. C. V. Avaliação de diferentes substratos para a formação de biofilmes in vitro de Pseudomonas aeruginosa. Disciplinarum Scientia, v. 16, n. 2, p. 191-203, 2015.

SILVA, A. F. S.; LIMA, C. A.; QUEIROZ, J. J. F.; JÁCOME, P. R. L. A.; JÁCOME-JÚNIOR, A. T. Análise bacteriológica das águas de irrigação de horticulturas. Revista Ambiente \& Água, v. 11, n. 2, 2016. http://dx.doi.org/10.4136/ambi-agua.1798

SIMÕES, L. C.; SIMÕES, M.; OLIVEIRA, R.; VIEIRA, M. J. Potential of the adhesion of bacteria isolated from drinking water to materials. Journal of Basic Microbiology, v. 47, p. 174-183, 2007. http://dx.doi.org/10.1002/jobm.200610224

TORVINEN, E.; LEHTOLA, M. J.; MARTIKAINEN, P. J.; MIETTINEN, I. T. Survival of Mycobacterium avium in Drinking Water Biofilms as Affected by Water Flow Velocity, Availability of Phosphorus, and Temperature. Applied and Environmental Microbiology, v. 73, n. 19, p. 6201-6207, 2007. http://dx.doi.org/10.1002/jobm.200610224 
WANG, H.; MASTERS, S.; EDWARDS, M. A.; FALKINHAM III, J. O.; PRUDEN, A. Effect of disinfectant, water age, and pipe materials on bacterial and eukaryotic community structure in drinking water biofilm. Environmental science \& technology, v. 48, n. 3, p. 1426-1435, 2014. http://dx.doi.org/10.1021/es402636u 